\title{
Representações sociais dos alunos do Ensino Médio sobre as práticas pedagógicas dos seus professores de História
}

\author{
Social representations of High School students on the pedagogical practices of \\ History teachers
}

\author{
Representaciones sociales de estudiantes de la Escuela Secundaria sobre las \\ prácticas pedagógicas de los profesores de Historia
}

\author{
Rosimeire Ferreira Diniz ${ }^{2}$ \\ Vânia Maria de Oliveira Vieira ${ }^{3}$
}

\begin{abstract}
Resumo: Esta pesquisa toma como objeto as práticas pedagógicas de professores de História, do Ensino Médio, na perspectiva dos alunos. De natureza quanti-qualitativa explicativa, busca na Teoria das Representações Sociais (TRS) de Moscovici (1978) o respaldo teórico-metodológico. Realizada com 76 alunos de três escolas públicas de Frutal/MG, apresenta como objetivo compreender as representações sociais (RS) construídas pelos alunos sobre as práticas pedagógicas dos seus professores de História. A coleta foi realizada a partir de um questionário contendo questões abertas e fechadas e a Técnica de Associação Livre de Palavras. Para as análises, além da TRS, contou-se com o auxílio do software EVOC e análise de conteúdo de Bardin (2011). Os resultados mostram que os alunos estão construindo RS ancoradas em elementos que evidenciam sentimentos dilemáticos - por um lado, reconhecem que o conhecimento e as provas são importantes para a formação; por outro, os procedimentos didáticos são cansativos e não auxiliam o processo de aprendizagem.
\end{abstract}

Palavras-chave: Práticas pedagógicas. Ensino Médio. Representações sociais.

\begin{abstract}
This research takes its object on the pedagogical practices of history teachers in high school, from the students' perspective. With an explanatory quanti-qualitative nature, it searches in Moscovici's Theory of Social Representations (1978) for theoretical and methodological support. Performed with 76 students from three public schools in Frutal / MG, its objective is to understand the social representations constructed by the students about the pedagogical practices of their History teachers. The collection was performed from a questionnaire containing open and closed questions and the Free Word Association Technique. For the analyzes, in addition to the TRS, the aid of EVOC software and content analysis by Bardin (2011) were supported. The results show that students are building SR based on elements that evidence dilemmatic feelings on one hand they recognize that knowledge and tests are important for training, on the other hand, the didactic procedures are tiring and do not help the learning process.
\end{abstract}

Keywords: Pedagogical practices. High school. Social Representations.

Resumen: Esta investigación toma como objeto las prácticas pedagógicas de los profesores de historia en la escuela secundaria, desde la perspectiva de los estudiantes. Con una naturaleza cuantitativa cualitativa explicativa, busca en la Teoría de las representaciones sociales (TRS) de Moscovici (1978) apoyo teórico y metodológico. Realizado con 76 estudiantes de tres escuelas públicas en Frutal / MG, su objetivo es comprender las representaciones sociales (RS) construidas por los estudiantes sobre las prácticas pedagógicas de sus profesores de Historia. La colección se realizó a partir de un cuestionario que contenía preguntas abiertas y cerradas y la técnica de asociación de palabras libres. Para los análisis, además del TRS, se apoyó la ayuda del software EVOC y el análisis de contenido de Bardin (2011). Los resultados muestran que los estudiantes están construyendo RS en base a elementos que muestran sentimientos dilemáticos; por un lado,

\footnotetext{
${ }^{1}$ Submetido em: 04 set. 2019 - Aceito em: 24 nov. 2019 - Publicado em: 27 nov. 2020

${ }^{2}$ Universidade de Uberaba (UNIUBE) - E-mail: rosimeireferreiradiniz@gmail.com

${ }^{3}$ Universidade de Uberaba (UNIUBE) - E-mail: vaninhaarquivos@gmail.com
} 
reconocen que el conocimiento y las pruebas son importantes para la capacitación, por otro lado, los procedimientos didácticos son agotadores y no ayudan al proceso de aprendizaje.

Palabras clave: Prácticas pedagógicas. Escuela secundaria. Representaciones sociale.

\section{Introdução}

Este estudo corrobora o pensamento de Krawczyk (2011, p. 754) quando afirma, com relação às reflexões sobre o sistema educacional brasileiro, a consensualidade de que o “ensino médio é o nível de ensino que provoca os debates mais controversos, seja pelos persistentes problemas do acesso e da permanência, seja pela qualidade da educação oferecida, ou, ainda, pela discussão sobre a sua identidade".

O cenário dos resultados das avaliações externas do Ensino Médio, apresentado nos últimos anos, também se mostra preocupante. De acordo com o Índice de Desenvolvimento da Educação Básica (IDEB), o Brasil encontra-se num patamar muito baixo, mostrando que os indicadores de fluxo do país não evoluem na velocidade desejada. Além disso, o Ensino Médio, segundo o Ministério da Educação (MEC) (BRASIL, 2017), é a etapa da vida escolar com o maior índice de evasão.

É nesse sentido que esta pesquisa busca colaborar com esse debate, ainda controverso. Sabemos que são muitos os fatores que podem contribuir para índices tão baixos, demonstrados nas pesquisas. Atentos à isso, dentre as diversas causas desse insucesso, elegemos, nesta pesquisa, o objeto de estudo "Práticas pedagógicas de professores de História do Ensino Médio", como um dos elementos que pode impactar a efetiva aprendizagem dos alunos. Portanto, por considerarmos que as práticas pedagógicas desenvolvidas pelos professores de História podem contribuir para a melhoria da educação no Ensino Médio, é que surge a proposta desta investigação a partir da seguinte questão problema: quais são as representações sociais dos alunos do Ensino Médio, sobre as práticas pedagógicas desenvolvidas por seus professores e que resultados essas práticas mostram na aprendizagem dos alunos? Isto é, a forma como o professor de História, das escolas públicas de Frutal/MG, realiza suas práticas pedagógicas, a partir do planejamento de ensino, da escolha das estratégias de aula, da avaliação e da maneira como se relaciona com os alunos, tem contribuído ou não para a aprendizagem escolar?

\section{Referencial teórico-metodológico e procedimentos}

\section{Teoria das Representações Sociais}

A Teoria das Representações Sociais (TRS), criada por Moscovici (1978), tem sua origem nos fundamentos teóricos das Representações Coletivas de Émile Durkheimi. Segundo Crusoé (2004, p. 106), “A discussão inicial de Durkheim sobre representações coletivas foi crucial para que Moscovici buscasse na sociologia um contraponto para a 
perspectiva individualista da psicologia social, tão presente na psicologia social da América do Norte". Na perspectiva de Moscovici (1978), as representações sociais, ao funcionarem como reguladoras e orientadoras do comportamento, permitem aos indivíduos comunicarem e compreenderem-se. Dessa maneira, uma das formas de compreender uma representação social é compreender a forma como um grupo a estrutura e a organiza cognitivamente, uma vez que dá uma explicação, um sentido à realidade.

Para Jodelet (2001, p. 22), discípula de Moscovici, a representação social “[...] é uma forma de conhecimento, socialmente elaborada e partilhada, com um objetivo prático, e que contribui para a construção de uma realidade comum a um conjunto social". Portanto, apresenta como finalidade, transformar o que é estranho, o que não é compreendido, em algo familiar. Compreendemos, assim, que as representações sociais são conjuntos de explicações, crenças, ideias que nos permitem recordar ou evocar acontecimento, pessoa ou objeto (VIEIRA, 2009).

Para Moscovici (2003), os processos de ancoragem e objetivação não ocorrem em momentos distintos, eles se desenvolvem ao mesmo tempo, se inter-relacionam e dão sentido à representação. Para esse autor, a ancoragem é o processo que "mantém a memória em movimento e a memória é dirigida para dentro; está sempre colocando e tirando objetos, pessoas e acontecimentos que ela classifica de acordo com um tipo e os rotula com um nome" (MOSCOVICI, 2003, p. 78). Por isso, é correto afirmar que esse processo, juntamente com a objetivação, podem ser considerados as maneiras de lidar com a memória. Quanto à objetivação, Moscovici (2003) esclarece que ela, por ser mais ou menos direcionada para fora, ou para os outros, pode ser compreendida como uma imagem, que, ao ser exposta no mundo exterior, torna possível conhecer coisas desconhecidas a partir do que já é conhecido.

\section{Teoria do Núcleo Central de Abric}

Abric (2003) e seus colaboradores desenvolveram o que chamaram de "Teoria do Núcleo Central", para entender a estrutura de uma representação social. Anunciam "que toda representação está organizada em torno de um núcleo central que é seu elemento fundamental e é ele quem determina sua significação e sua organização" (BERTONI; GALINKIN, 2017, p. 111).

O Núcleo Central, segundo Abric (2003), tem especial importância por ser responsável pela elaboração, manutenção e atualização das representações. Para Sá (2002, p. 62):

[...] a organização de uma representação apresenta uma característica particular: não apenas os elementos da representação são hierarquizados, mas, além disso, toda representação é organizada em torno de um Núcleo Central, constituído de um ou de alguns elementos que dão à representação o seu significado.

Segundo Sá (1996, p. 22), o sistema periférico, constituído pelos demais elementos de uma representação, promove a "interface entre a realidade concreta e o sistema central [...]". Isto é, para o autor, o sistema periférico "atualiza e contextualiza as determinações 
normativas e consensuais do sistema central [...], daí resultando a mobilidade, a flexibilidade e a expressão individualizada das representações sociais" (SÁ, 1996, p. 22).

Assim, ao compreendermos como esses significados se organizam num determinado grupo, no nosso caso, os alunos do Ensino Médio, será possível verificar até que ponto essas representações sobre as práticas dos professores de História norteiam as ações dos indivíduos; o que constitui, no nosso entendimento, uma possibilidade de leitura de questões que envolvem a realidade educacional. A escolha dessa teoria para a compreensão do objeto de estudo desta pesquisa, as práticas pedagógicas dos professores de História do Ensino Médio, permitirá não só, por meio de sua abordagem, conhecer as construções sociais da realidade pesquisada, que influenciam e guiam o comportamento dos professores e alunos, como também construir conhecimentos, que podem possibilitar discussões e reflexões acerca dos questionamentos apontados neste estudo - práticas pedagógicas e aprendizagem dos alunos.

\section{Os procedimentos metodológicos}

Este estudo utiliza uma abordagem quanti-qualitativa, conceituada por Creswell e Creswell (2010, p. 4) como "um procedimento de coleta, análise e combinação de técnicas quantitativas e qualitativas em um mesmo desenho de pesquisa". Para esses autores, o que justifica o uso dessa abordagem é a interação entre eles; o que possibilita melhores condições de análises.

O estudo foi realizado em três escolas estaduais de Educação Básica de Frutal/MG, situadas em diferentes regiões e com maior número de alunos. Os participantes foram os alunos do $3^{\circ}$ ano de três turmas do Ensino Médio, totalizando 76 participantes das respectivas escolas. Para a coleta dos dados, utilizou-se um questionário ${ }^{i i}$ contendo questões abertas e fechadas e a Técnica de Associação Livre de Palavras (TALP). Essa técnica foi tratada pelo software EVOC, com base no método Vergès (2002), que apresenta como finalidade combinar a frequência com a ordem de emissão das palavras. O EVOC busca identificar nas Representações Sociais os elementos centrais e periféricos.

Quanto à análise dos dados, o estudo contou não só com o referencial teóricometodológico da Teoria das Representações Sociais, como também com o auxílio do software EVOC, que tem como finalidade organizar as evocações realizadas na TALP, de acordo com a ordem de aparecimento. E, para orientação do processo de categorização das respostas das questões abertas, utilizamos, também, os fundamentos da análise de conteúdo descritos por Bardin (2011). Essa autora recomenda percorrer três momentos: Pré-análise, Exploração do material e o Tratamento dos resultados. $\mathrm{O}$ primeiro momento foi dedicado à organização do material - escolhemos os documentos que foram analisados, formulamos hipóteses e elaboramos os indicadores. O segundo, a etapa mais longa e cansativa, consistiu em tomar as decisões iniciadas na pré-análise. Foi o momento de codificação em que elegemos as categorias. E, a última, o tratamento dos resultados, realizamos a inferência e a interpretação dos dados. 


\section{Práticas pedagógicas de professores do Ensino Médio: um diálogo teórico}

Para a compreensão do termo "práticas pedagógicas", recorremos ao que afirma Franco (2016, p. 541): “as práticas pedagógicas se organizam intencionalmente para atender a determinadas expectativas educacionais solicitadas/requeridas por uma dada comunidade social". Para essa autora, é comum os termos "práticas educativas" e "práticas pedagógicas", serem tratados como sinônimos, no entanto, há diferenças. Práticas educativas referem-se "às práticas que ocorrem para a concretização de processos educacionais". Já, quando se trata de práticas pedagógicas, objeto desta pesquisa, está se referindo às "práticas sociais exercidas com a finalidade de concretizar processos pedagógicos" (FRANCO, 2016, p. 536).

Neste estudo, consideramos como práticas pedagógicas o planejamento do professor; os procedimentos didáticos, ou seja, as estratégias ${ }^{\mathrm{iii}}$ de ensino; a avaliação do processo ensino-aprendizagem; e, a interação professor-aluno.

\section{O planejamento de Ensino}

É inegável a importância do planejamento de ensino. Muitos autores, dentre eles, Gandin (2002), reforçam o significado dessa ação e a sua importância na orientação do trabalho do professor e da instituição de ensino em que atua. $O$ autor afirma que é fundamental tanto o professor quanto a instituição assumirem a responsabilidade diante do planejamento das atividades escolares. Destaca, ainda, que em um processo de planejamento, são três as perguntas básicas a serem feitas e retomadas continuamente, de forma lógica: "O que queremos alcançar? A que distância estamos daquilo que queremos alcançar? O que faremos concretamente, num prazo determinado, para diminuir essa distância?" (GANDIN, 2002, p. 21). Assim, ao fazer essas perguntas, propostas pelo autor, pode-se perceber a importância do planejamento de aula.

Considerando que aula pressupõe uma prática político-pedagógica-intencional, no processo ensino-aprendizagem, a falta de planejamento pode ter como consequência aulas monótonas, desorganizadas e desestimulantes, o que, consequentemente, pode provocar no aluno a falta de interesse em aprender, em participar e se envolver. Ora, se não há planejamento, no qual se expressa essa intencionalidade, o processo de aprendizagem pode ficar comprometido. Nesse sentido, o planejamento permite não só realizar previsões do que se deseja alcançar através dos objetivos, como também possibilita definir os resultados desses objetivos que se deseja alcançar.

\section{Procedimentos didáticos}

Neste estudo, chamamos de procedimentos didáticos os recursos, ou seja, as estratégias, os métodos de ensino ou a metodologia que o professor utiliza para ministrar a sua aula. 
Para Roldão (2009, p. 3), as estratégias de ensino podem ser compreendidas como um "conjunto organizado de ações para a melhor consecução de uma determinada aprendizagem". De modo geral, as estratégias referem-se aos meios utilizados pelos professores para ministrar suas aulas e articular o processo ensino-aprendizagem. Para isso, Anastasiou e Alves $(2004$, p. 71) recomendam que as estratégias devam visar à consecução de objetivos; portanto, "há que ter clareza sobre aonde se pretende chegar naquele momento com o processo de ensino. Por isso, os objetivos que norteiam devem estar claros para os sujeitos envolvidos - professores e alunos".

Referindo-se aos procedimentos didáticos do professor de História, Fonseca (2003) recomenda que, durante o desenvolvimento da aula, a discussão e a problemática do tema devem ser tratadas de forma que os estudantes encontrem significado no conteúdo que aprendem. Isso faz com que os alunos assumam uma atitude positiva e motivadora na construção do conhecimento.

\section{A avaliação}

Para conceituar avaliação, é preciso primeiro compreender a concepção que se tem de avaliar. Numa concepção mais "tradicional” e que, segundo Luckesi (2002), ainda é comum em nossas escolas, a avaliação é caracterizada pela objetividade dos resultados e dos instrumentos que se utilizam; prioriza-se a avaliação do conhecimento; há uma preocupação maior em aprovar ou reprovar. Nessa concepção, há pouca participação dos sujeitos envolvidos, o que importa é o resultado demonstrado.

Para Libâneo (1994, p. 195): “A avaliação é uma tarefa didática necessária e permanente do trabalho docente, que deve acompanhar passo a passo o processo de ensino e aprendizado". Dito com outras palavras, são os resultados da avaliação, obtidos no decorrer do trabalho do professor, indicando progresso ou dificuldades, que orientarão o processo de ensino-aprendizagem.

A avaliação escolar, na concepção de Sousa (1994, p. 89), “também chamada avaliação do processo ensino-aprendizagem ou avaliação do rendimento escolar, tem como dimensão de análise o desempenho do aluno, do professor e de toda a situação de ensino que se realiza no contexto escolar". Pode-se dizer que, para Sousa (1994), a avaliação tem como finalidade auxiliar o professor e toda a equipe escolar. Sobre isso, Vieira (2009) explica que a avaliação da aprendizagem, nessa concepção, deixa de ser sinônimo de mensuração, pois não há preocupação técnica de medir o rendimento do aluno. A autora acrescenta, ainda, que a avaliação nesse contexto "[...] tem como função oferecer dados que permitam ao professor conhecer o que o aluno já aprendeu e o que ele ainda não aprendeu, para providenciar os meios para que ele aprenda o necessário e dê continuidade aos estudos" (VIEIRA, 2009, p. 9).

Para Villas Boas (2004, p. 35), "a avaliação formativa é a que usa todas as informações disponíveis sobre o aluno para assegurar a sua aprendizagem". Com relação a isso, vale ressaltar a importância de o professor utilizar diferentes e diversos instrumentos para avaliar, pois, ao 
dispor apenas de provas escritas, os resultados podem ficar comprometidos por falta de dados necessários ao processo avaliativo.

\section{Relação aluno-professor}

Concordamos com Veras e Ferreira (2010, p. 220), quando afirmam que a "tradicional valorização da dimensão cognitiva em detrimento da afetiva, na trajetória do pensamento e do conhecimento humano [...] tem dificultado a compreensão das relações entre ensino e aprendizagem". Para essas autoras, isso tem limitado o processo de aprendizagem dos alunos em todos os níveis de ensino.

Como mostra Freire (1996), a relação professor-aluno, de uma forma ou de outra, influencia o processo educacional. Em razão disso, Tiba (1998) reforça a necessidade de o educador conhecer as diferenças dos seus alunos e os diferentes tipos de linguagens que podem ser utilizadas, não só para ensinar o conteúdo escolar, mas também para proporcionar ao educando o conhecimento de si mesmo, a busca da autoconfiança, do engajamento e da motivação necessária à aprendizagem significativa.

Libâneo (1994) também valoriza a interação professor-aluno. Para ele, a ação pedagógica tem consequências individuais e sociais na condução do processo ensino-aprendizagem. Assim, a forma como esse processo é realizado, a partir das escolhas das atividades escolares e da forma como se estabelecem as relações do professor com o aluno, na execução das atividades escolares, pode facilitar ou não o ensino-aprendizagem.

\section{O diálogo com os dados}

Inicialmente, traçamos o perfil dos alunos, em seguida, analisamos as questões abertas e fechadas do questionário, para identificarmos as representações sociais dos alunos sobre as práticas pedagógicas desenvolvidas pelos seus professores e, por último, a partir da Técnica de Associação Livre de Palavras, identificamos, com o auxílio do software EVOC, o Núcleo Central e Sistema Periférico das Representações.

\section{Perfis dos participantes}

Participaram da pesquisa 76 estudantes; todos cursando o $3^{\circ}$ ano do Ensino Médio. A maioria é do sexo feminino (64\%) e mora com os pais ou um dos pais $(93,8 \%)$, em residência própria $(81,5 \%)$. A maioria dos pais possui apenas o Ensino Fundamental e Médio e uma porcentagem preocupante ( $21 \%$ dos pais e $18,4 \%$ das mães) nunca frequentou a escola. Motorista (21\%) e Pedreiro (9,2\%) são as profissões dos pais que lideram a pesquisa. Do mesmo modo, do lar $(19,7 \%)$ e doméstica $(11,8 \%)$ lideram as profissões das mães. Esses dados encontram relação com a escolaridade dos pais, em que a maioria só possui Ensino Fundamental ou Médio. Para se manterem informados sobre os acontecimentos atuais, 
utilizam, principalmente, as redes sociais - o Google, o Facebook e o Instagram. Há uma diversidade de opções quanto às atividades de interesse dos alunos; dentre elas, destacam-se: uso das tecnologias de comunicação e informação, navegar na internet $(85,5 \%)$ e jogos online (56,5\%), bem como também há interesse relacionado com o convício social: ir à festas (78,9\%), conversar com amigos (71\%), ir ao cinema (43,4\%), praticar esportes $(40,7 \%)$ e ir ao shopping $(39,4 \%)$. Demonstram um sentimento positivo com relação à escola, uma vez que afirmam gostar da escola $(65,7 \%)$ e serem bem tratados pelos professores $(43,4 \%)$.

\section{As práticas pedagógicas dos professores na visão dos alunos}

\section{O planejamento de ensino}

Sobre o planejamento de ensino dos professores, não há um consenso entre os participantes. Embora 34,2\% afirmem que o planejamento prevê objetivos, conteúdos e métodos a partir da realidade; $25 \%$ parecem compreender que seus professores não têm hábito de realizar o planejamento, que decidem, no início da aula, o que vai ser dado. Há também um dado preocupante quando $27,6 \%$ dos alunos assinalaram a opção "não tenho conhecimento sobre o planejamento realizado pelos meus professores"; o que pode parecer que, para os alunos, o planejamento e todas as questões que o envolvem não são socializados pelos seus professores.

Relacionada com os dados dessa questão, encontramos, na pesquisa de Scarinci e Pacca (2015, p. 260), a afirmação de que, embora o processo de planejamento de ensino do professor deva ser "entendido como um processo de pensar o ensino e a aprendizagem, seus objetivos e suas condições de concretização", o que se vê atualmente são processos sendo realizados apenas como ação burocrática e não "como valioso instrumento de reflexão para o professor" (SCARINCI; PACCA, 2015, p. 260).

Indagamos, também, sobre os conteúdos estudados na disciplina de História. A maioria $(42,1 \%$ e $34,2 \%)$, respectivamente, afirma que o conteúdo é "desinteressante" e "pouco aplicado a prática". Os demais $(9,2 \%)$ assinalaram que "sua aprendizagem permite aplicá-lo no nosso dia a dia"; com a mesma porcentagem, 9,2\% afirmam que "integra teoria e prática" e apenas $2,6 \%$ o consideram "motivador e interessante".

Esses dados parecem ser preocupantes e se assemelham à questão anterior, podendo indicar que o planejamento não é discutido nem socializado com os alunos e, como afirmam Scarinci e Pacca (2015), constitui uma ação meramente burocrática.

\section{Os procedimentos didáticos ou estratégias de ensino}

Para investigar sobre os procedimentos didáticos utilizados pelos professores, solicitamos o preenchimento de uma tabela a partir das seguintes informações:

A Tabela 01, com cinco colunas, apresenta, na $1^{\mathrm{a}}$, algumas estratégias e/ou procedimentos didáticos. Leia-as com atenção e assinale: 
- $\mathrm{Na} 2^{\mathrm{a}}$ coluna, as estratégias e/ou procedimentos didáticos que seus professores de História mais utilizam nas aulas.

- $\mathrm{Na} 3^{\mathrm{a}}$ coluna, as estratégias e/ou procedimentos didáticos já utilizadas pelos seus professores de História e que facilitam a sua aprendizagem.

- $\mathrm{Na} 4^{\mathrm{a}}$ coluna, assinale as estratégias e/ou procedimentos didáticos já utilizados pelos seus professores de História e que não facilitam a sua aprendizagem.

- $\mathrm{Na} 5^{\mathrm{a}}$ coluna, assinale as estratégias e/ou procedimentos didáticos que seus professores de História não utilizam e você gostaria que utilizassem.

Tabela 1. Com relação às estratégias e/ou procedimentos didáticos utilizados pelos professores ${ }^{\text {iv }}$

\begin{tabular}{|c|c|c|c|c|}
\hline $1^{\text {a }}$ coluna & $2^{\mathrm{a}}$ coluna & $3^{a}$ coluna & $4^{a}$ coluna & $5^{\mathrm{a}}$ coluna \\
\hline $\begin{array}{c}\text { Estratégias e/ou } \\
\text { procedimentos didáticos. }\end{array}$ & $\begin{array}{c}\text { Mais } \\
\text { utilizadas } \\
\text { pelos meus } \\
\text { professores } \\
\text { de História. }\end{array}$ & $\begin{array}{l}\text { Utilizadas pelos } \\
\text { meus } \\
\text { professores e } \\
\text { facilitam a } \\
\text { minha } \\
\text { aprendizagem. }\end{array}$ & $\begin{array}{c}\text { Utilizadas pelos } \\
\text { meus } \\
\text { professores e } \\
\text { não facilitam a } \\
\text { minha } \\
\text { aprendizagem. }\end{array}$ & $\begin{array}{c}\text { Meus } \\
\text { professores não } \\
\text { utilizam, mas } \\
\text { gostaria que } \\
\text { utilizassem. }\end{array}$ \\
\hline a) Aula expositiva dialogada & 42 & 27 & 16 & 15 \\
\hline b) Estudo de texto & 30 & 32 & 13 & 13 \\
\hline c) Livro didático & 41 & 32 & 8 & 13 \\
\hline d) Apostila & 5 & 8 & 5 & 47 \\
\hline e) Data show & 15 & 28 & 11 & 25 \\
\hline f) Portfólio & 2 & 4 & 6 & 37 \\
\hline g) Mapa conceitual & 1 & 7 & 7 & 48 \\
\hline h) Estudo dirigido & 12 & 9 & 14 & 32 \\
\hline i) Atividade virtual & 2 & 6 & 4 & 46 \\
\hline j) Resolução de exercícios & 36 & 28 & 10 & 16 \\
\hline k) Atividades em grupo & 29 & 30 & 19 & 17 \\
\hline 1) Dramatização & 12 & 3 & 12 & 26 \\
\hline m) Seminário & 13 & 21 & 14 & 25 \\
\hline n) Estudo de caso & 7 & 7 & 7 & 39 \\
\hline o) Júri simulado & 1 & 4 & 3 & 49 \\
\hline p) Simpósio & 2 & 3 & 2 & 43 \\
\hline q) Painel & 3 & 4 & 5 & 40 \\
\hline r) Palestras & 5 & 12 & 7 & 27 \\
\hline s) Fórum & 2 & 2 & 15 & 45 \\
\hline t) Discussão e debate & 21 & 24 & 2 & 21 \\
\hline u) Oficina & 2 & 0 & 9 & 44 \\
\hline v) Ensino com pesquisa & 15 & 19 & 6 & 26 \\
\hline w) Excursões e visitas & 2 & 6 & 3 & 57 \\
\hline $\mathrm{x})$ Jogos & 2 & 1 & 2 & 54 \\
\hline $\begin{array}{l}\text { y) Ensino } \\
\text { individualizado }\end{array}$ & 11 & 8 & 10 & 28 \\
\hline
\end{tabular}

Fonte: Elaborado pela autora a partir dos dados da pesquisa (2018). 
A partir dos dados coletados, podemos realizar as seguintes análises:

a) Quanto às estratégias mais utilizadas pelos professores de História. A aula expositiva (42), o livro didático (41) e a resolução de problemas (36) foram as estratégias mais citadas pelos alunos como sendo as mais utilizadas pelos professores. Alguns alunos reconhecem também que essas estratégias facilitam a aprendizagem.

b) Quanto às estratégias utilizadas pelos professores e que facilitam a aprendizagem. No que se refere a esse grupo, os alunos citam o estudo de texto (32), o uso do data show (28) e as atividades em grupo (30) como sendo as que mais facilitam a aprendizagem. Embora essas estratégias não tenham sido apontadas como sendo as mais utilizadas pelos professores, em algumas, pode-se observar que há um número expressivo deles que as utilizam. $O$ estudo de texto foi citado por 30 alunos como sendo utilizado pelos seus professores. Já o data show, apenas 15 alunos citaram como sendo utilizado pelos seus professores, enquanto 13 afirmaram que o uso dele facilita a aprendizagem, mas não o apontaram como sendo utilizado pelos professores. Quanto às atividades em grupo, há um certo equilíbrio; 29 afirmam que são utilizadas pelos professores e 30 a reconhecem como facilitadora da aprendizagem.

c) Quanto às estratégias utilizadas pelos professores e que não facilitam a aprendizagem. A atividade em grupo (19), a aula expositiva (16) e o fórum (15) foram as mais citadas como sendo as estratégias que são utilizadas pelos professores e que não facilitam a aprendizagem. Enquanto 19 alunos citam a atividade em grupo como sendo uma estratégia que não facilita a aprendizagem, 30 pensam o contrário, afirmam que facilita a aprendizagem. O mesmo ocorre com a aula expositiva, embora 27 alunos afirmem que essa estratégia facilita a aprendizagem, 16 pensam o contrário. Quanto ao fórum, enquanto 15 alunos afirmam que essa estratégia não facilita a aprendizagem, outros 45 se contrapõem a essa afirmação assinalando a opção: "Meus professores não utilizam, mas gostaria que utilizassem".

d) Quanto às estratégias que os professores não utilizam, mas gostariam que utilizassem. Excursões e visitas (57), jogos (54) e júri simulado (49) foram as mais assinaladas como sendo as estratégias que os professores não utilizam, mas os alunos gostariam que utilizassem. Como pode ser observado, essas estratégias guardam em comum o fato de serem atividades dinâmicas, que demandam participação ativa de todos os alunos.

Sintetizando, podemos inferir também que, para os alunos, há muitos procedimentos didáticos ou estratégias de ensino que deveriam ser utilizados pelos seus professores de História, por facilitarem a aprendizagem, mas ainda não são, como: apostila, portfólio, mapa conceitual, estudo dirigido, atividade virtual, dramatização, seminário, estudo de caso, júri simulado, simpósio, painel, palestras, fórum, oficina, ensino com pesquisa, excursões e visitas, jogos e ensino individualizado.

Esses dados podem sinalizar, também, que os professores não têm conseguido diversificar as estratégias de ensino para ministrar as suas aulas, embora o estudo de texto, o uso do data show, as atividades em grupo, a discussão e o debate sejam reconhecidos por eles 
como constituintes de procedimentos didáticos utilizados pelos seus professores e que facilitam a aprendizagem.

Vale lembrar, nesse sentido, o que aponta Masetto (1997, p. 95), ao referir-se às estratégias de ensino: "não existem técnicas boas ou ruins. Temos estratégias adequadas (ou inadequadas) aos objetivos que pretendemos alcançar".

\section{A avaliação da aprendizagem}

Para a maioria dos participantes, a avaliação é realizada pelos seus professores de História com o objetivo de "pressionar os alunos a estudar", quesito assinalado por 40,4\%, e para "acompanhar o processo de aprendizagem e verificar o que aprendemos ou não", assinalado por $30,2 \%$ dos alunos. Na sequência, 18,4\% afirmam que é para reprovar ou aprovar os alunos. $11,8 \%$ dos participantes que assinalaram a opção "outros" não a identificaram.

Se, por um lado, alguns participantes compreendem que a avaliação tem por finalidade acompanhar o processo de aprendizagem para verificar o que o aluno aprendeu ou não, o que pode ser indício de construção de representações positivas com relação a essa prática, por outro, torna-se preocupante a maioria afirmar que a avaliação é para pressionar os alunos a estudar e para reprovar ou aprovar. Essa concepção de avaliação, como visto anteriormente, não faz parte de uma avaliação formativa.

Preocupante, também, é o fato de apenas 2,6\% dos participantes citarem a inclusão da "autoavaliação", e a opção "utiliza diferentes instrumentos para avaliar" não ter sido assinalada por nenhum aluno; o que pode sinalizar presença de representações negativas. Sobre a importância de utilizar diferentes instrumentos para avaliar o aluno, vale retomar Villas Boas (2004, p. 35), quando aponta que "a avaliação formativa é a que usa todas as informações disponíveis sobre o aluno para assegurar a sua aprendizagem”.

\section{Relação professor-aluno como prática pedagógica}

Buscamos compreender quais as qualidades dos professores eram percebidas pelos alunos; como se sentiam durante as aulas; e como tem sido a construção das representações sociais sobre a autoridade do professor.

Embora 32,8\% não reconheçam nenhuma qualidade dos professores, pois assinalaram a opção "nenhuma das opções acima", e também nenhum aluno assinalou a opção "mostram interesse pelo nosso aprendizado", há contraposição de 35,5\%, ao afirmarem que "são disponíveis para esclarecer as nossas dúvidas" e de 14,4\%, ao assinalarem que "dão-nos oportunidade para expor nossas opiniões nas aulas". Assim, considerando que nenhum aluno afirma que os professores mostram interesse pelo aprendizado do aluno, em relação a esses dados há indícios da existência de dois grupos de representações, ou seja, a relação professoraluno é representada ora positiva ora negativa. 
A opção "os meus professores de História mostram interesse pelo nosso aprendizado" não foi assinalada por nenhum aluno, e apenas $40 \%$ disseram que ficam à vontade para fazer perguntas aos professores. Os demais, 36,8\%, afirmaram que ficam perdidos durante a explicação do professor, e $22,3 \%$ se sentem estranhos durante as aulas. Ora, ficam perdidos, ou sentem-se como estranhos também pode ter relação com os procedimentos que não são utilizados pelos professores, mas que eles gostariam que fossem.

Quanto à representação de autoridade, os dados mostram que a maioria $(38,1 \%)$ assinalou a opção "utilizam uma autoridade que impõe, com postura autoritária, inflexível e arrogante". $\mathrm{Na}$ sequência, contrastando a anterior, $25 \%$ dos alunos afirmam que os professores utilizam uma autoridade que é "fruto de suas qualidades intelectuais, morais e técnicas, exercida como um estímulo e ajuda para o desenvolvimento independente dos alunos". Apenas 10,5\% afirmaram que seus "professores utilizam uma autoridade capaz de conduzir os interesses comuns dos alunos". E 17,1\% assinalaram a opção "meus professores não possuem autoridade no desenvolvimento das ações pedagógicas".

Desse modo, a relação professor-aluno, se, por um lado pode apresentar elementos que a identifiquem como positiva, por outro, evidencia indícios de que tais representações possam estar ancoradas em elementos negativos. Sobre isso, Leite (2006, p. 149) corrobora nossas análises, afirmando que: "O que se diz, como se diz, em que momento e por que - da mesma forma que o que se faz, como se faz, em que momento e por que - afetam profundamente as relações professor e aluno e consequentemente, influenciam o processo de ensino aprendizagem". Nesse sentido, a relação professor-aluno, na disciplina de História, por ser reconhecida por alguns alunos como uma relação autoritária e arrogante, pode influenciar, como afirma Leite (2006), o processo de aprendizagem dos alunos.

\section{Técnica de associação livre de palavras - o EVOC}

A partir do termo indutor “As práticas pedagógicas dos meus professores de História”, os participantes escreveram cinco palavras. Dessas cinco, apontaram a mais importante e, em seguida, justificaram a escolha. Solicitamos, também, que escrevessem os sinônimos das outras quatro. Após o tratamento das palavras evocadas, em que foi realizado um trabalho para identificação e substituição das que tinham o mesmo significado, a lista foi transcrita em uma tabela no Excel e processada no EVOC. Desse processamento resultou a figura de 4 casas. 
Figura 1. Quadro do EVOC - Núcleo Central e Sistema Periférico

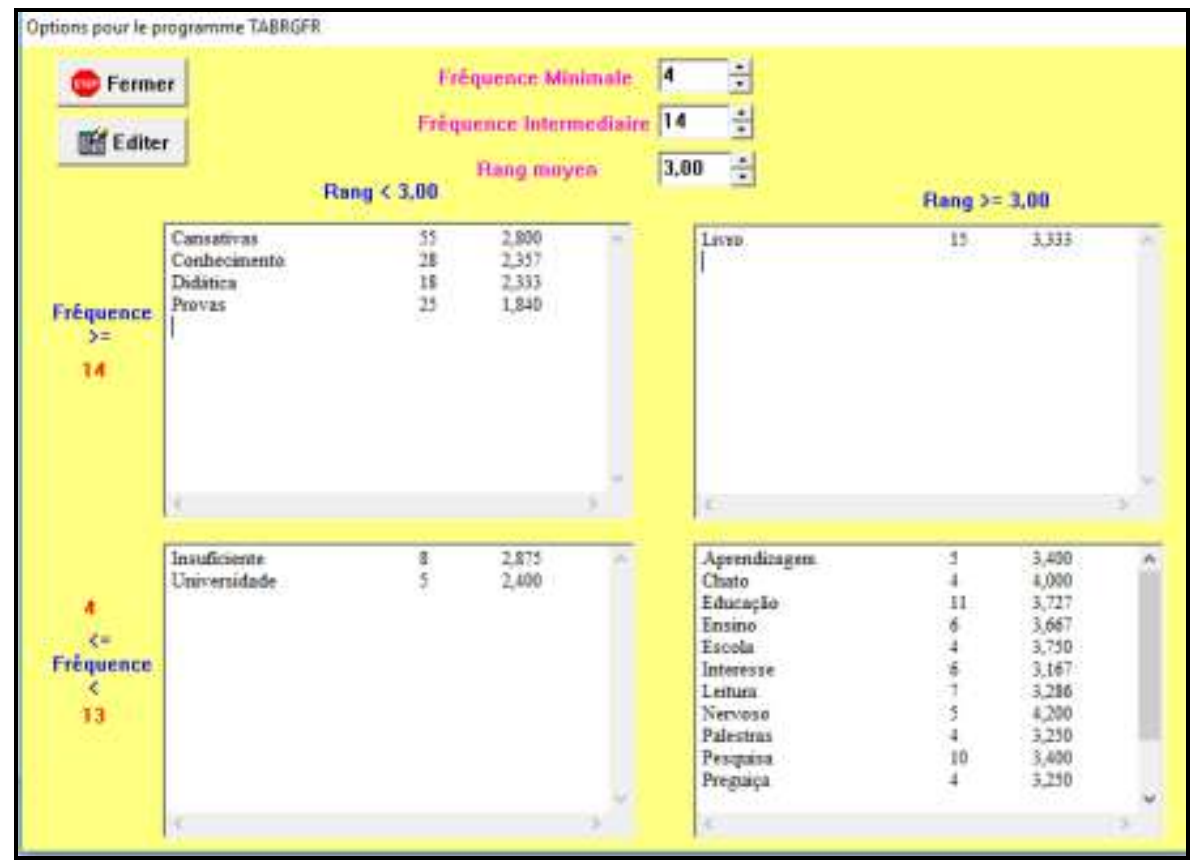

Fonte: EVOC.

Quanto à utilização do software EVOC, a TALP forneceu um total de 380 palavras. Desse total, as palavras pouco frequentes não são consideradas nem interessam para a análise das evocações. Assim, estabelecemos uma frequência mínima para a inclusão das palavras, que foi 4 , e o cálculo de uma frequência intermediária, que foi 14. A frequência média foi determinada a partir da frequência acumulada inversa, considerando a que corresponde à frequência acumulada de 50\% (ou próxima dela). Desse modo, o Software considerou 50\% das palavras mais frequentes. A frequência intermediária foi obtida dividindo-se a soma das frequências consideradas pelo número de palavras que correspondeu a essas frequências. A etapa que operacionaliza essa fase do Software recebe a denominação de Rang, que ficou estipulada em 3,0 .

Com relação ao quadro do EVOC (Figura 1), o primeiro quadrante superior esquerdo constitui o provável Núcleo Central das representações. No segundo, superior direito, estão os elementos intermediários, ou primeira periferia. No terceiro, inferior esquerdo, estão os elementos de contraste. E, no quarto, inferior direito, estão os elementos da segunda periferia.

\section{Primeiro quadrante - o núcleo central}

Compõem esse quadrante as palavras Cansativas, Conhecimento, Provas e Didática. Essas palavras foram evocadas com maior frequência (maior que 14) e, provavelmente, constituem o núcleo central das representações.

A palavra cansativa, a mais evocada (55), traz, nas justificativas e sinônimos dos participantes, a compreensão de que, para eles, as práticas pedagógicas dos seus professores de História não auxiliam a aprendizagem escolar. Isto é, são cansativas, desinteressantes, 
desgastantes e causam sono, uma vez que os professores utilizam apenas métodos maçantes, não há inovação, como pode ser observado nos exemplos: "É muito cansativo e causa desinteresse" (L7); "Pois usa métodos muito maçantes" (L17).

Com relação à aula ser cansativa, o estudo de Ribeiro e Ribeiro (2011), sobre a sala de aula como um espaço/tempo de produção de conhecimento, mostra a necessidade de o professor não resistir às tecnologias educacionais inovadoras. Para esses autores, "É inadiável a inovação no modo de ensinar e de aprender" (RIBEIRO; RIBEIRO, 2011, p. 76).

Do contexto da palavra conhecimento (28), pode-se perceber que, para os alunos, a prática pedagógica dos seus professores, contrariando o significado da palavra anterior, cansativa, ancora em elementos positivos que podem favorecer a aprendizagem. Para esse grupo, conhecimento tem relação com aprender (M8), conteúdo (M10), aprendizagem (M13), saber (M15), pesquisa (M21), explicação (V24), necessário (V21). Para Leal, Novais e Fernandez (2015, p. 725): “É reconhecido que o conhecimento do conteúdo específico desempenha um papel importante dentre a base de conhecimentos para o ensino".

A palavra Prova (25), para os alunos, tem relação com os sinônimos: avaliação (V3), aprendizagem (V4), estudo (V5), conhecimento (V7), essencial (V21) e ansiedade (V8). Nas justificativas, encontramos a compreensão de que as provas, além de serem uma forma de saber o que realmente foi aprendido, são também um meio de saber sobre o ensino que é passado pelo professor. "Porque avalia o conhecimento do aluno" (V2).

A forma como os participantes descrevem os sentimentos com relação à prova demonstra também relação com os princípios de avaliação formativa, uma vez que esse tipo de avaliação apresenta como objetivo possibilitar aos alunos uma aprendizagem com compreensão dos processos vivenciados por eles e, ao mesmo tempo, permite ao professor analisar e refletir sobre os processos de aprendizagem oferecidos aos alunos (VILLAS BOAS, 2013).

A palavra Didática (18), no contexto das justificativas, guarda relação com o modo como os professores ministram suas aulas. Afirmam que: "A forma como a didática é passada para os alunos muita das vezes é desinteressante e monótona" (V23). Sobre a didática, ou estratégias de ensino, Moreira (2014, p. 16) mostra que o professor deve utilizar "estratégias que desafiam as capacidades dos alunos, organizando atividades de ensino que atendam às características do conteúdo, dos cursos, da disciplina e dos alunos envolvidos no processo".

\section{Sistema periférico}

Os demais quadrantes do EVOC constituem o sistema periférico das representações sociais. Esse sistema contém os elementos mais flexíveis e adaptáveis. Ainda não são considerados representações sociais, são apenas indícios, mas podem vir a ser, isto é, podem migrar para o Núcleo Central.

Vale lembrar, nessa periferia, a palavra Livros, com alta frequência, presente no segundo quadrante ou primeira periferia. Essa palavra mostra, a partir dos sinônimos e 
justificativas, que, para os alunos participantes, as práticas pedagógicas dos seus professores lembram o livro didático e trazem uma conotação positiva, isto é, ele ajuda no desenvolvimento da aula.

\section{Considerações finais}

Partimos da hipótese de que a forma como o professor realiza suas práticas pedagógicas, a partir do planejamento de ensino, da escolha das estratégias de aula, da avaliação e da maneira como se relaciona com os alunos, pode contribuir ou não para a aprendizagem escolar. E, assim, procuramos desvendar, na perspectiva dos alunos, as implicações das práticas pedagógicas dos professores sobre a aprendizagem escolar. A ideia principal foi a de pensar as práticas pedagógicas dos professores associadas aos sujeitos que aprendem. E foi o que fizemos. Procuramos dar voz aos alunos com o intuito de compreender questões ligadas ao processo ensino-aprendizagem realizado por meio das práticas pedagógicas desenvolvidas pelos professores.

No que diz respeito às representações sociais dos participantes, sobre as práticas pedagógicas desenvolvidas pelos seus professores de História, sinteticamente podemos dizer que, embora algumas sejam vistas como facilitadoras do processo de aprendizagem, outras já não são.

Diante de tais resultados e das possibilidades de análises realizadas neste estudo, propomos algumas sugestões para enfrentamento do problema enunciado no início desta pesquisa. Essas sugestões, como bem lembra Marcelo García (1999), não devem ser entendidas como ações pontuais e esporádicas de formação, mas, consideradas dentro de um processo que pode ser reconhecido, de fato, como desenvolvimento profissional docente. Importa, por conseguinte, lembrar que, para esse autor, o desenvolvimento profissional docente pode ser conceituado como "o conjunto de processos e estratégias que facilitam a reflexão dos professores sobre a sua prática, que contribui para que os professores gerem conhecimento prático, estratégico e sejam capazes de aprender com sua experiência" (MARCELO GARCÍA, 1999, p. 144). É nessa perspectiva que, apontamos sugestões que possam ser realizadas a partir de momentos formativos institucionalizados pela própria escola. São elas:

a) Socializar o planejamento escolar com os alunos, bem como a escolha e a relevância do conteúdo curricular;

b) Estudar e conhecer diferentes procedimentos didáticos que possam facilitar a aprendizagem dos alunos;

c) Trocar, com os pares, experiências de procedimentos didáticos exitosos que contribuíram para a aprendizagem dos alunos;

d) Compreender a avaliação da aprendizagem como um processo de avaliação formativa; 
e) Refletir sobre a relação professor-aluno e sua implicação no processo de ensinoaprendizagem.

Ademais, ao darmos voz aos alunos, observamos algumas questões que, ainda, necessitam ser problematizadas e melhor compreendidas. Essas questões perpassam as práticas pedagógicas dos professores, assim como o processo de formação e desenvolvimento profissional docente. Nesse sentido, as análises sugerem continuidade desse estudo.

\section{Referências}

ABRIC, Jean-Claude. A abordagem estrutural das representações sociais: desenvolvimentos recentes. In: CAMPOS, Pedro Humberto Faria; LOUREIRO, Marcos Corrêa da Silva (org.). Representações sociais e práticas educativas. Goiânia: Editora UCG, 2003. p. 37-57.

ANASTASIOU, Léa das Graças Camargos; ALVES, Leonir Pessate. Estratégias de ensinagem. In: ANASTASIOU, Léa das Graças Camargos; ALVES, Leonir Pessate (org.). Processos de ensinagem na universidade: pressupostos para as estratégias de trabalho em aula. 3. ed. Joinville: Univille, 2004. p. 67-100.

BARDIN, Laurence. Análise de conteúdo. São Paulo: Edições 70, 2011.

BERTONI, Luci Mara; GALINKIN, Ana Lúcia. Teoria e métodos em representações sociais. In: MORORÓ, Leila Pia; COUTO, Maria Elizabete Souza; ASSIS, Raimunda Alves Moreira de (org.). Notas teórico-metodológicas de pesquisas em educação: concepções e trajetórias. Ilhéus, BA: EDITUS, 2017. p. 101-122.

BRASIL. Evasão no ensino médio supera 12\%, revela pesquisa inédita. Brasília: Ministério da Educação, 20 de junho de 2017. Disponível em: http://portal.mec.gov.br/ultimas-noticias/211-218175739/50411-evasao-no-ensino-mediosupera-12-revela-pesquisa-inedita. Acesso em: 02 set. 2019.

CRESWELL, John W.; CRESWELL, J. David. Projeto de pesquisa: métodos qualitativo, quantitativo e misto. 3. ed. Porto Alegre: Artmed, 2010.

CRUSOÉ, Nilma Margarida de Castro. A teoria das representações sociais em Moscovici e sua importância para a pesquisa em educação. APRENDER - Caderno de Filosofia e Psicologia da Educação, Vitória da Conquista, ano II, n. 2, p. 105-114, jan./jun. 2004.

FONSECA, Selva Guimarães. Didática e prática de ensino de História: experiências, reflexões e aprendizados. Campinas: Papirus, 2003.

FRANCO, Maria Amélia do Rosario Santoro. Prática pedagógica e docência: um olhar a partir da epistemologia do conceito. Revista Brasileira de Estudos Pedagógicos, Brasília, v. 97, n. 247, p. 534-551, set./dez. 2016. https://doi.org/10.1590/S2176-6681/288236353.

FREIRE, Paulo. Pedagogia da autonomia: saberes necessários à prática educativa. São Paulo: Paz e Terra, 1996. 
GANDIN, Danilo. Planejamento como prática educativa. São Paulo: Loyola, 2002.

JODELET, Denise. Representações sociais: um domínio em expansão. In: JODELET, Denise (org.). As representações sociais. Rio de Janeiro: EdUERJ, 2001. p. 17-44.

KRAWCZYK, Nora. Reflexão sobre alguns desafios do ensino médio no Brasil hoje. Cadernos de Pesquisa, São Paulo, v. 41, n. 144, p. 752-769, set./dez. 2011. https://doi.org/10.1590/S0100-15742011000300006.

LEAL, Sérgio Henrique; NOVAIS, Robson Macedo; FERNANDEZ, Carmen. Conhecimento pedagógico do conteúdo de "estrutura da matéria" de uma professora de química experiente em aulas de química geral. Ciência \& Educação, Bauru, v. 21, n. 3, p. 725-742, 2015. https://doi.org/10.1590/1516-731320150030013.

LEITE, Sérgio Antonio da Silva (org.). Afetividade e práticas pedagógicas. 1. ed. São Paulo: Casa do Psicólogo, 2006.

LIBÂNEO, José Carlos. Didática. São Paulo: Cortez Editora, 1994.

LUCKESI, Cipriano Carlos. Avaliação da aprendizagem escolar. 14. ed. São Paulo: Cortez, 2002.

MARCELO GARCÍA, Carlos. Formação de professores: para uma mudança educativa. 2. ed. Porto: Porto Editora, 1999.

MASETTO, Marcos Tarcísio. Didática: a aula como centro. 1. ed. São Paulo: FTD Educação, 1997.

MOREIRA, Ana Elisa da Costa. Relações entre as estratégias de ensino do professor, com as estratégias de aprendizagem e a motivação para aprender de alunos do Ensino Fundamental I. 2014. 118 f. Dissertação (Mestrado em Educação) - Universidade Estadual de Londrina, Londrina, 2014.

MOSCOVICI, Serge. A representação social da psicanálise. Tradução de Álvaro Cabral. Rio de Janeiro: Zahar, 1978.

MOSCOVICI, Serge. Representações sociais: investigações em psicologia social. Tradução de Pedrinho A. Guareschi. Petrópolis: Vozes, 2003.

RIBEIRO, Victoria Maria Brant; RIBEIRO, Adriana Maria Brant. A aula e a sala de aula: um espaço-tempo de produção de conhecimento. Revista do Colégio Brasileiro de Cirurgiões, Rio de Janeiro, v. 38, n. 1, p. 71-76, 2011. https://doi.org/10.1590/S0100$\underline{69912011000100013}$.

ROLDÃO, Maria do Céu. Estratégias de ensino: o saber e o agir do professor. Vila Nova de Gaia, PT: Fundação Manuel Leão, 2009.

SÁ, Celso Pereira de. Núcleo central das representações sociais. Petrópolis: Vozes, 2002. 
SÁ, Celso Pereira de. Representações sociais: teoria e pesquisa do núcleo central. Temas em Psicologia, Ribeirão Preto, v. 4, n. 3, p. 19-33, dez. 1996.

SCARINCI, Anne Louise; PACCA, Jesuína Lopes de Almeida. O planejamento do ensino em um programa de desenvolvimento profissional docente. Educação em Revista, Belo Horizonte, v. 31, n. 2, p. 253-279, abr./jun. 2015. https://doi.org/10.1590/0102-4698120707.

SOUSA, Clarilza Prado (org.). Avaliação do rendimento escolar. São Paulo: FDE, 1994.

TIBA, Içami. Ensinar aprendendo: como superar os desafios do relacionamento professoraluno em tempo de globalização. São Paulo: Editora Gente, 1998.

VERAS, Renata da Silva; FERREIRA, Sandra Patrícia Ataíde. A afetividade na relação professor-aluno e suas implicações na aprendizagem, em contexto universitário. Educar em Revista, Curitiba, n. 38, p. 219-235, set./dez. 2010. https://doi.org/10.1590/S0104$\underline{40602010000300015 .}$.

VÈRGES, Pierre. Conjunto de programas que permitem a análise de evocações: EVOC: manual. Versão 5. Aix en Provence: 2002.

VIEIRA, Vânia Maria de Oliveira. Avaliação educacional: algumas contribuições teóricas para a formação de professores. Revista profissão docente, Uberaba, v. 8, n. 17, p. 120-151, ago./dez. 2009.

VILLAS BOAS, Benigna Maria de Freitas (org.). Virando a escola do avesso por meio da avaliação. 1. ed. Campinas: Papirus, 2013.

VILLAS BOAS, Benigna Maria de Freitas. Portfólio, avaliação e trabalho pedagógico. Campinas: Papirus, 2004.

\section{Notas}

i “Émile Durkheim (1858-1917) foi um sociólogo francês. É considerado o pai da Sociologia Moderna e chefe da chamada Escola Sociológica Francesa. É o criador da teoria da coesão social. Junto com Karl Marx e Max Weber, formam um dos pilares dos estudos sociológicos". Fonte: https://www.ebiografia.com/emile_durkheim/.

ii Os questionários foram aplicados nas próprias escolas, em horários cedidos pelos professores. Para isso, solicitamos aos pais dos alunos a assinatura dos Termos de Consentimento Livre e Esclarecido, aprovados pelo Comitê de Ética em Pesquisa envolvendo Seres Humanos da UNIUBE, CAAE: 01603318.1.0000.5145 e também a assinatura dos Termos de Assentimentos pelos alunos.

iii A opção pelas expressões "estratégias de ensino" e "métodos de ensino", como sinônimos, inicialmente, ocorreu durante a realização do teste com o instrumento de coleta de dados (questionário). Nessa ocasião, foi observado que essas expressões eram melhor compreendidas pelos alunos. Em seguida, observamos também que essas expressões são as mais utilizadas pelos autores que tratam dessa temática.

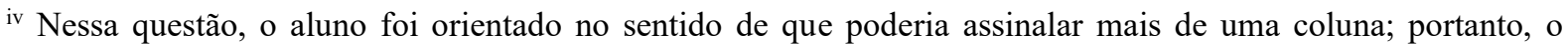
número total de respostas não confere com o número de participantes.
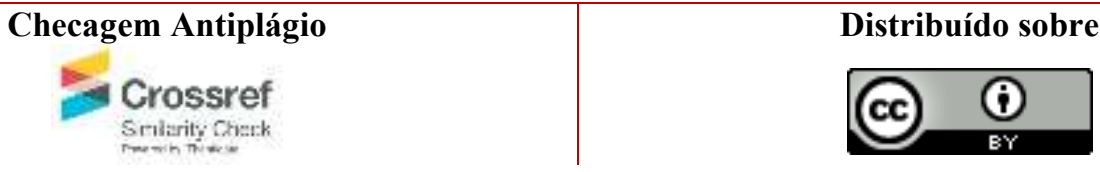